Review article

\title{
Selected rare paediatric communication neurological disorders
}

\author{
Blanka Klimova ${ }^{1}$, Martin Valis ${ }^{1}$, Jakub Hort ${ }^{2,3}$, Kamil Kuca ${ }^{4,5}$ * \\ ${ }^{1}$ University Hospital Hradec Kralove, Department of Neurology, Hradec Kralove, Czech Republic \\ ${ }^{2}$ Charles University in Prague, 2nd Faculty of Medicine and University Hospital Motol, Memory Disorders Clinic, Department of Neurology, Prague, \\ Czech Republic \\ ${ }^{3}$ St. Anne's University Hospital Brno, International Clinical Research Center, Brno, Czech Republic \\ ${ }^{4}$ University of Hradec Kralove, Faculty of Science, Department of Chemistry, Hradec Kralove, Czech Republic \\ ${ }^{5}$ University Hospital Hradec Kralove, Biomedical Research Centre, Hradec Kralove, Czech Republic
}

\begin{abstract}
The purpose of this review is to discuss rare neurological disorders with respect to communication difficulties typical of children. Firstly, communication disorders with special focus on rare communication neurological disorders are discussed. Secondly, on the basis of literature review, the authors explore clinical studies on the most typical rare children's communication neurological disorders. Thirdly, on the basis of the findings from the clinical studies, they set a few recommendations for their medical therapies and management. The methodology was based on the literature review of research studies exploring the research issue. The findings show that the intervention strategies appear to have positive effects on the improvement of speech and language production among children suffering from LandauKleffner syndrome and childhood apraxia of speech. Nevertheless, randomized control trials are needed in order to accelerate and facilitate an early and relevant diagnosis and treatment management. In addition, a multidisciplinary approach seems to be the most appropriate for the accurate diagnosis and comprehensive treatment.
\end{abstract}

Keywords: Childhood apraxia of speech; Communication; Landau-Kleffner syndrome; Language; Neurological disorders; Treatment

\section{Introduction}

As the European Commission on Public Health (2017) states, rare diseases $(R D)$ are life-threatening or chronically debilitating diseases, which are of such low prevalence that special combined efforts are needed to address them. Thus, for instance, in Europe the disease is considered rare if one person out of 2000 people is affected, while in the USA it is one person out of 200000 (Rare Diseases Act of 2002, 2002). Currently, 5400 rare diseases listed in the Orphanet database have an endorsed representation in the foundation layer of the International Classification of Diseases (ICD) 11 and rare neurological disorders with neurocognitive impairment as a major feature are one of them (Aime et al., 2015). Neurological disorders form $50 \%$ of RD (Federico, 2013). Similarly, as other RD, only a few of them have treatments, therefore sometimes RD are also called orphan diseases. Generally, only 5\% of all RD have medical therapies (Kubackova et al., 2014). 2002 products have orphan drug designation with 352 drugs being provided with Food and Drug Administration (FDA) approval (Maresova et al., 2016). Thanks to a specific regulation of orphan drugs, their number is gradually increasing year by year. It is estimated that each year there should be between 8-12 new orphan drugs (Kubackova et al., 2014).

Rare neurological diseases represent a heterogeneous group of disorders which predominantly affect the central and peripheral nervous systems and muscle. They often result in severe disability, possibly in death. Although they are relatively rare, their social and economic impact can be compared with other chronic neurological diseases such as stroke or Parkinson's disease (Dodel et al., 2004). The basic clinical units include Wilson's disease, Huntington's disease, amyotrophic lateral sclerosis, rare dystonic syndromes, heredoataxia of children and adult age, leukodystrophy, neurocutaneous diseases, and other rare diseases (Kubackova et al., 2014).

The purpose of this mini-review is to discuss rare neurological disorders with respect to communication difficulties typical of children. Firstly, communication disorders with special focus on rare communication neurological disorders are discussed. Secondly, on the basis of literature review, the authors explore clinical studies on the most typical rare children's communication neurological disorders. Thirdly, on the basis of the findings from the clinical studies, they set a few recommendations for their medical therapies and management.

\footnotetext{
* Author for correspondence: Kamil Kuca, University Hospital Hradec Kralove, Biomedical Research Centre, Sokolska 581, 50005 Hradec Kralove, Czech Republic; e-mail: kamil.kuca@fnhk.cz http://doi.org/10.32725/jab.2018.002

Submitted: 2018-03-20 • Accepted: 2018-09-24 • Prepublished online: 2018-11-23

J Appl Biomed 17/1: 29-33 • EISSN 1214-0287 • ISSN 1214-021X

(c) 2018 The Authors. Published by University of South Bohemia in České Budějovice, Faculty of Health and Social Sciences.

This is an open access article under the CC BY-NC-ND license.
} 


\section{Materials and methods}

The methods included a literature review of research studies exploring rare communication neurological disorders with special focus on rare children's communication neurological disorders, their classification, medical therapies and management, and an analysis of their results. The search for the key words rare diseases, orphan diseases, rare neurological disorders, and rare neurological diseases, was conducted PubMed, Scopus, and Web of Knowledge in the period of 2000 to 2015. The selection began in the year of 2000 because after this year research studies on this research topic started to be published. The authors of this mini-review also researched the case reports and descriptive studies. In addition, for the definition of communication disorders and their classification, review studies and web pages of the most important organizations in this field were searched.

Altogether 140 studies were detected. Most of them were found in PubMed - 70 research studies, which was then followed by Scopus -59 studies. After removing some of them for their duplicity, analysing their titles and abstracts, 34 studies remained for the full-text analysis and eventually seven studies were identified for the detailed analysis. Nevertheless, the remaining studies were then used in the manuscript in order to compare and discuss the results.

\section{Communication disorders - their definition and classification with special focus on rare communication neurological disorders}

ASHA (1982) defines a communication disorder as an impairment in the capability to receive, send, process, and understand concepts or verbal, nonverbal and graphic symbol systems. This may be manifested in the process of hearing, language, and/or speech. A communication impairment can be of different degree of severity, from mild to severe. Furthermore, it can be developmental or acquired. People may possess only one or several communication disorders. A communication disorder may result in a primary disability or it may be secondary to other disabilities. Altogether there are four main types of communication disorders: speech disorders, language disorders, hearing disorders, and central auditory processing disorders.

- Speech disorders are impairments of the articulation of speech sounds, fluency and/or voice. They may be caused by oral-motor difficulties, although some include language processing problems.

- Language disorders can be understood as an impaired language system, involving word finding, word retrieval or anomia, i.e. the processing of linguistic information. These disorders may affect the form, content, as well as function of communication. They usually result in an irrelevant use of words and their meaning; inability to convey ideas, an inappropriate use of grammatical word forms, and a lack of semantic and pragmatic language functions (Klimova et al., 2015; Krapp, 2002).

- Hearing disorders are the result of impaired auditory sensitivity of the physiological auditory system. These hearing impairments can reduce the development, understanding, production, and/or maintenance of speech and/or language. They are categorized according to the difficulties in detection, recognition, discrimination, understanding, and perception of auditory information. People with hearing disorders can be divided into deaf (another channel for communication is used) or hard of hearing (the auditory channel is still used for communication).

- Central auditory processing disorders (CAPD) are insufficiencies in the processing of information of audible signals, not attributed to impaired peripheral hearing sensitivity or intellectual impairment. This information processing includes perceptual, cognitive, and linguistic functions that, with appropriate interaction, cause effective receptive communication of auditorily presented stimuli. Specifically, CAPD refers to the reduced ability of ongoing transmission, analysis, organization, transformation, elaboration, storage, retrieval, and use of information contained in audible signals.

It is the left hemisphere of the brain which is particularly connected with the speech and language functions. There are two specific areas of the brain whose damage causes the speech and language impairments. Those are the Broca's area in the posterior frontal lobe and the Wernicke's area in the temporal lobe. Harm to Broca's area causes difficulties with fluency, while harm to Wernicke's area affects speech which is fluent, however, it lacks content (Longe, 2011).

Apart from the common speech and language disorders such as dysarthria or aphasia (Klimova and Kuca, 2016a), which can be also part of the symptoms of rare neurological diseases such as Huntington's disease, there are less common or even rare communication neurological disorders such as dysprosody, Jacobsen syndrome, or spasmodic dysphonia, which cannot be unfortunately cured. Dysprosody, or the socalled foreign accent syndrome (FAS), is a rare medical disorder in which people affected by the brain injury lose the ability to speak in their native accent and acquire a foreign accent, even if they have never travelled to that country. The key symptoms involve longer and distorted vowel sounds, different movement of tongue or jaw when speaking, using wrong words to describe something, inability to make a proper sentence, or behavioral changes corresponding to the nationality of the new accent (Marien and Verhoeven, 2007). Jacobsen syndrome is a multiple congenital anomaly/mental retardation (MCA/MR) contiguous gene syndrome caused by partial deletion of the long arm of chromosome 11. To date, over 200 cases have been reported in the literature. The prevalence is estimated at $1 / 100000$ births, with a female/male ratio of $2: 1$. The most common clinical features include pre- and postnatal growth retardation, psychomotor retardation, and a characteristic facial dysmorphism (skull deformities, hypertelorism, ptosis, coloboma, downslanting palpebral fissures, epicanthal folds, a broad nasal bridge, short nose, V-shaped mouth, and small, low-set and posteriorly rotated ears). Abnormal platelet function, thrombocytopenia or pancytopenia are usually present at birth. Patients commonly have malformations of the heart, kidney, gastrointestinal tract, genitalia, central nervous system and skeleton. Ocular, auditory, immunological and hormonal anomalies may be also present (Orphanet, 2009). Spasmodic dysphonia is a voice disorder characterized by involuntary movements or spasms of one or more muscles of the larynx (vocal folds or voice box) during speech. Although it can start at any time during life, SD seems to begin more often when people are middle-aged. The disorder affects women more often than men. Its incidence is very low, 1 per 100000 cases. The onset is usually gradual with no obvious explanation. Symptoms usually occur in the absence of any structural abnormality of the larynx, such as nodules, polyps, carcinogens, or inflammation. People have described their symptoms 
as worsening over an approximate 18-month period and then remaining stable in severity from that point onward (Ludlow, 2011; Tisch et al., 2003).

In order to limit the scope of this study on rare communication neurological disorders, the authors of this review explore clinical trials describing the most typical rare children's communication neurological disorders. These include acquired infantile aphasia and childhood apraxia of speech.

\section{Results}

The review on the most typical rare children's communication disorders include acquired infantile aphasia, the so-called Landau-Kleffner syndrome (LKS) and childhood apraxia of speech (CAS). Childhood apraxia of speech, also known as developmental verbal dyspraxia, is a rare speech disorder when a child has difficulties making accurate movements while speaking. The reason is that the brain has difficulty controlling or coordinating the movement of speech muscles (Velleman, 2003). The main symptoms of CAS include difficulties in prosody when performing lexical or phrasal stress, vowel distortions, such as attempting to use the correct vowel, but saying it incorrectly, putting a pause between syllables, thus separating them, inconsistency in making errors when saying the same word or phrase again, or difficulties in imitating simple words (Campbell, 2003). CAS might develop as a result of known neurological impairment, in association with complex neurobehavioral disorders of known and unknown origin, or as an idiopathic neurogenic speech sound disorder. Its incidence is 1-2 children in 1000, and it is more typical of boys than girls (Lewis et al., 2004).

LKS is defined as a childhood-acquired epileptic aphasia whose incidence is between the ages of 3 and 10 (peak age 5-7 years). It is a quite dangerous and abrupt auditory processing disorder that starts as acquired verbal auditory agnosia in a child who was previously developmentally normal (Fandino et al., 2001). In 90\% of children a receptive aphasia appears first, then subsequently a rapid and severe reduction of spontaneous speech occurs. It affects slightly more boys than girls. While many affected individuals have clinical seizures, some only have electrographic seizures, including electrographic status epilepticus of sleep. This disease usually stabilizes before the adulthood (Kleffner and Landau, 2009). Unfortunately, the pathology of LKS, as well as other paediatric epilepsies, is not yet known (Lotte, 2006).

Table 1 below then summarizes the intervention outcomes and their efficacy of both rare communication disorders. The study was included into this review if it was a clinical trial, written in English, directly connected to these two rare communication disorders and covered the period of 2000-2015. Altogether seven clinical trials were identified. The studies are ranked alphabetically according to their first author and according to the corresponding paediatric communication neurological disorder.

Table 1. Specifications of the intervention outcomes of clinical trials on childhood apraxia of speech and Landau-Kleffner syndrome (authors' own processing)

\begin{tabular}{|c|c|c|c|c|}
\hline Study & Objective & $\begin{array}{l}\text { Number of } \\
\text { subjects }\end{array}$ & Type of intervention & Findings \\
\hline \multicolumn{5}{|l|}{ CAS } \\
\hline $\begin{array}{l}\text { Dale and } \\
\text { Hayden (2013) }\end{array}$ & $\begin{array}{l}\text { To evaluate the efficacy of the } \\
\text { Prompts for Restructuring Oral } \\
\text { Muscular Phonetic Targets } \\
\text { (PROMPT) treatment program. }\end{array}$ & $\begin{array}{l}\text { Four children } \\
\text { aged between } \\
3.6 \text { and } 4.8 \text { years. }\end{array}$ & $\begin{array}{l}\text { PROMPT treatment } \\
\text { approach and tactile- } \\
\text { kinesthetic-proprioceptive } \\
\text { (TKP) cues. }\end{array}$ & $\begin{array}{l}\text { The findings show a considerable } \\
\text { improvement in motor speech control and } \\
\text { untreated word profiles when TKP is also } \\
\text { included. }\end{array}$ \\
\hline $\begin{array}{l}\text { Maas et al. } \\
\text { (2012) }\end{array}$ & $\begin{array}{l}\text { To examine the role of feedback } \\
\text { frequency in treatment for CAS. }\end{array}$ & Four children. & Frequency of feedback. & $\begin{array}{l}\text { There might be benefits in reducing the } \\
\text { frequency of feedback for some children with } \\
\text { CAS. }\end{array}$ \\
\hline $\begin{array}{l}\text { Maas and } \\
\text { Farinella (2012) }\end{array}$ & $\begin{array}{l}\text { To compare the effects of } \\
\text { random versus blocked practice } \\
\text { schedules in treatment of CAS. }\end{array}$ & Four children. & $\begin{array}{l}\text { Random versus blocked } \\
\text { practice schedules. }\end{array}$ & $\begin{array}{l}\text { The findings show that the random practice } \\
\text { schedules might not be effective for children } \\
\text { with CAS. }\end{array}$ \\
\hline $\begin{array}{l}\text { Preston et al. } \\
\text { (2013) }\end{array}$ & $\begin{array}{l}\text { To evaluate the efficacy of } \\
\text { a treatment program with } \\
\text { ultrasound biofeedback for } \\
\text { CAS. }\end{array}$ & $\begin{array}{l}\text { Six children (aged } \\
\text { between } 9 \text { and } \\
15 \text { years). }\end{array}$ & $\begin{array}{l}18 \text { treatment session } \\
\text { focused on producing } \\
\text { sequences comprising } \\
\text { lingual sounds. }\end{array}$ & $\begin{array}{l}\text { This treatment program with ultrasound } \\
\text { biofeedback is an effective option for } \\
\text { improving speech sound accuracy in children } \\
\text { with CAS. }\end{array}$ \\
\hline $\begin{array}{l}\text { Thomas et al. } \\
\text { (2014) }\end{array}$ & $\begin{array}{l}\text { To explore the efficacy of } \\
\text { twice-weekly Rapid Syllable } \\
\text { Transitions (ReST) treatment } \\
\text { program for children with CAS. }\end{array}$ & $\begin{array}{l}\text { Four children } \\
\text { (aged between } \\
4 \text { and } 8 \text { years). }\end{array}$ & $\begin{array}{l}\text { ReST treatments twice a } \\
\text { week for six weeks. }\end{array}$ & $\begin{array}{l}\text { The findings show that children acquired } \\
\text { new skills and generalize them to untreated } \\
\text { items. They even maintained these skills after } \\
\text { the end of treatment for the follow-up four } \\
\text { months. }\end{array}$ \\
\hline
\end{tabular}

Landau-Kleffner syndrome

\begin{tabular}{ll}
\hline Kossoff et al. & $\begin{array}{l}\text { To explore the efficacy of } \\
\text { leviteracetam monotherapy on } \\
\text { language functions in children } \\
\text { with benign rolandic epilepsy } \\
\text { (BRE). }\end{array}$
\end{tabular}

Sinclair and To examine the efficacy

Snyder (2005) of corticosteroids for the treatment of LKS and spikewave discharge.

$\begin{array}{lll}\text { Six children aged } & 40 \mathrm{mg} / \mathrm{kg} / \text { day } & \text { Leviteracetam had a positive effect on the } \\ \text { between } 6 \text { and } 12 & \text { leviteracetam. } & \text { improvement of auditory verbal memory. }\end{array}$
years.

10 children aged $1 \mathrm{mg} / \mathrm{kg} /$ day prednisone. between 2 and 11 years.
The findings show the improvement in patients' language, cognition and behavior. 


\section{Discussion}

Although the clinical trials are sparse since these communication neurological disorders are considered rare and their diagnostics is quite difficult, the findings of this mini-review show that the intervention strategies generally appear to have positive effects on the improvement of speech and language production. As far as CAS is concerned, majority of treatment approaches focus on the improvement of motor speech skills and linguistic skills (cf. Murray et al., 2014). The results of this review illustrate three such approaches: PROMPT treatment together with cues (Dale and Hayden, 2013), ultrasound biofeedback treatment when a patient can see an ultrasound image showing the correct tongue placement (Preston et al., 2013), and ReST treatment focusing on the accuracy of speech sound production and rapid and fluent transitioning from one sound or syllable to the next one (Thomas et al., 2014). Furthermore, there are motor-programming or rhythmic (prosodic) approaches (ASHA, 2017). In addition, the findings on CAS also indicate that the frequency of feedback (Maas et al., 2012) and practice schedules (Maas and Farinella, 2012) when enhancing children's speech should be considered. Research studies (e.g. Winter, 2008) also point out that children with CAS have literacy difficulties in the areas of writing and reading, which should be involved in the intervention treatment programs.

Apart from these traditional treatment approaches, alternative strategies have recently appeared to be beneficial (Klimova and Kuca, 2016b). The study by Beathard and Krout (2008), for example, proposes a music therapy for the treatment of children with CAS. The authors claim that the music therapy can enhance production of syllables, combination of sounds and words. Another study by Hession et al. (2014) proves that a horse riding therapy might be stimulating for children with CAS in terms of the improvement of their cognition, mood, and gait. Nevertheless, more randomized control trials are needed to show the efficacy of all these treatment approaches such as the ongoing trial by Murray et al. (2012) during which the researchers explore the efficacy of the ReST treatment program and the Nuffield Dyspraxia Program.

As far as the treatment of LKS is concerned, there are three common approaches, which include the administration of drugs such as clobazam or diazepam; oral steroids such as prednisone and the anti-epileptic drugs, the so-called anticonvulsants (Guevara-Campos and González-de Guevara, 2007; Mikati and Shamseddine, 2005). In this mini-review the efficacy of prednisone (Sinclair and Snyder, 2005) and leviteracetam (Kossoff et al., 2007), a novel drug with improved tolerance and safety ( $\mathrm{Li}$ et al., 2014), proved to have a positive effect on cognitive functions such as the auditory verbal memory. If these medications are not effective, sometimes intravenous immunoglobulin therapy is applied (Fandino et al., 2011). However, in all cases speech therapy is essential, which should be intensive and focus on the residual language skills and teaching language in a developmental pattern; sign language as an alternative method of communication due to the auditory verbal agnosia might be implemented; visual input with pictures, color coding, and drawings on note cards on the desk for scheduling is recommended; or computer programs with colorful visuals and simple verbal information to assist in learning decoding skills might be used as well (Fandino et al., 2011).

The main limitations of this mini-review consist in small samples of subjects, a lack of control groups, and biases in the included publications, which appear to be a serious threat to the validity of the research studies (cf. Melby-Lervag and Hulme, 2013; 2016).

\section{Conclusion}

The findings have shown that these paediatric communication neurological disorders are rare and involve many factors such as deficits in sensorimotor, cognition, language, learning and effective processes, therefore a multidisciplinary approach seems to be the most appropriate for the right and accurate diagnosis and comprehensive treatment. Moreover, relevant and early treatment management may avoid speech and language deterioration.

\section{Conflict of interests}

The authors have no conflicts of interests to declare.

\section{Acknowledgements}

This work was supported by MH CZ - DRO (UHHK 00179906), PROGRES Q40 run at the Medical Faculty Charles University, and by the long-term development plan UHK.

\section{References}

Aime S, Bellet B, Rath A (2015). Rare diseases in ICD 11: Making rare diseases visible in health information systems through appropriate coding. Orphanet J Rare Dis 10, 35. DOI: 10.1186/ s13023-015-0251-8.

ASHA (1982). Definitions-communicative disorders and variations. American Speech-Language-Hearing Association. 24(11): 949-950.

ASHA (2017). Childhood apraxia of speech. [online] [cit. 201712-20]. Available from: http://www.asha.org/PRPSpecificTopic. aspx?folderid=8589935338\&section=Treatment.

Beathard B, Krout RE (2008). A music therapy clinical case study of a girl with childhood apraxia of speech. The Arts in Psychotherapy. 35(2): 107-116. DOI: 10.1016/j.aip.2008.01.004.

Campbell TF (2003). Childhood apraxia of speech: Clinical symptoms and speech characteristics. In: Shriberg LD, Campbell TF (Eds). Proceedings of the 2002 Childhood Apraxia of Speech Symposium. The Hendrix Foundation, Carlsbad, pp. 37-40.

Dale PS, Hayden DA (2013). Treating speech subsystems in childhood apraxia of speech with tactual input: the PROMPT approach. Am J Speech Lang Pathol 22(4): 644-666. DOI: 10.1044/1058-0360(2013/12-0055).

Dodel R, Peter H, Walbert T, Spottke A, Noelker C, Berger K, et al. (2004). The socioeconomic impact of narcolepsy. Sleep 27(6): 1123-1128.

European Commission on Public Health (2017). Useful information on rare diseases from an EU perspective. [online] [cit. 2017-1220]. Available from: http://ec.europa.eu/health/ph_information/ documents/ev20040705_rd05_en.pdf

Fandino M, Connoly M, Usher L, Palm S, Kosak FK (2011). Landau/ Kleffner syndrome: a rare auditory processing disorder series of cases and review of the literature. Int J Pediatr Otorhinolaryngol 75: 33-38. DOI: 10.1016/j.ijporl.2010.10.001.

Federico A (2013). Rare neurological diseases: a Pandora's box for neurology (an European and Italian perspective). Rev Neurol 169(Suppl. 1): S12-S17. DOI: 10.1016/S0035-3787(13)70054-7.

Guevara-Campos J, González-de Guevara L (2007). Landau-Kleffner syndrome: an analysis of 10 cases in Venezuela. Rev Neurol 44(11): 652-656.

Hession CE, Eastwood B, Watterson D, Lehane CM, Oxley N, Murphy BA (2014). Therapeutic horse riding improves cognition, mood arousal, and ambulation in children with dyspraxia. J Altern Complement Med 20(1): 19-23. DOI: 10.1089/acm.2013.0207. 
Kleffner FR, Landau WM (2009). The Landau-Kleffner syndrome. Epilepsia 50(Suppl. 7): 4.

Klimova B, Kuca K (2016a). Speech and language impairments in dementia - a mini-review. J Appl Biomed 14(2): 97-103. DOI: 10.1016/j.jab.2016.02.002.

Klimova B, Kuca K (2016b). Multi-nutrient dietary intervention approach to the management of Alzheimer's disease - a minireview. Curr Alzheimer Res 13(12): 1312-1318.

Klimova B, Maresova P, Valis M, Hort J, Kuca K (2015). Alzheimer's disease and language impairments: Social intervention and medical treatment. Clin Interv Aging 10: 1401-1408. DOI: $10.2147 / C I A . S 89714$.

Kossoff EH, Los JG, Boatman DF (2007). A pilot study transitioning children onto levetiracetam monotherapy to improve language dysfunction associated with benign rolandic epilepsy. Epilepsy Behav 11(4): 514-517. DOI: 10.1016/j.yebeh.2007.07.011.

Krapp KM (2002). The Gale Encyclopedia of Nursing \& Allied Health. 6 th edition. Gale Group, Detroit.

Kubackova K, et al. (2014). Vzacna onemocneni v kostce. [Rare Diseases in a Nutshell.] Mlada fronta, a. s., Praha (Czech).

Lewis BA, Freebairn LA, Hansen A, Taylor HG, Iyengar SK, Shriberg LD (2004). Family pedigrees of children with suspected childhood apraxia of speech. J Commun Disord 37: 157-175. DOI: 10.1016/j.jcomdis.2003.08.003.

Li Z, Gao Z, Jin C, Guo Q, Wang L, Shandan W, et al. (2014). The efficacy of leviteracetam versus carbamazepine for epilepsy: a meta-analysis. Iran J Public Health 43(12): 1616-1626.

Longe JL (2011). The Gale Encyclopedia of Children's Health: Infancy through Adolescence. 2nd ed. Gale Group, Detroit.

Lotte N (2006). The pathophysiological mechanisms of cognitive and behavioral disturbances in children with Landau-Kleffner syndrome or epilepsy with continuous spike-and-waves during slow-wave sleep. Seizure 15: 249-258. DOI: 10.1016/j. seizure.2006.02.008.

Ludlow CL (2011). Spasmodic dysphonia: a laryngeal control disorder specific to speech. The J Neurosci 31(3): 793-797. DOI: 10.1523/JNEUROSCI.2758-10.2011.

Maas E, Butalla CE, Farinella KA (2012). Feedback frequency in treatment for childhood apraxia of speech. Am J Speech Lang Pathol 21(3): 239-257. DOI: 10.1044/1058-0360(2012/11-0119).

Maas E, Farinella KA (2012). Random versus blocked practice in treatment for childhood apraxia of speech. J Speech Lang Hear Res 55(2): 561-578. DOI: 10.1044/1092-4388(2011/11-0120).

Maresova P, Klimova B, Kuca K (2016). Financial and legislative aspects of drug development of orphan diseases on the European market - a systematic review. Applied Economics 48(27): 25622570. DOI: 10.1080/00036846.2015.1125433.

Marien P, Verhoeven J (2007). Cerebellar involvement in motor speech planning: some further evidence from foreign accent syndrome. Folia Phoniatr Logop 59(4): 210-217. DOI: $10.1159 / 000102933$.
Melby-Lervåg M, Hulme C (2013). Is working memory training effective? A meta-analytic review. Dev Psychol 49(2): 270-291. DOI: $10.1037 / \mathrm{a} 0028228$.

Melby-Lervåg M, Hulme C (2016). There is no convincing evidence that working memory training is effective: A reply to Au et al. (2014) and Karbach and Verhaeghen (2014). Psychon Bull Rev 23(1): 324-330. DOI: 10.3758/s13423-015-0862-z.

Mikati MA, Shamseddine AN (2005). Management of LandauKleffner syndrome. Paediatr Drugs 7(6): 377-389.

Murray E, McCabe P, Ballard KJ (2012). A comparison of two treatments for childhood apraxia of speech: methods and treatment protocol for a parallel group randomized control study. BMC Pediatr 12: 112. DOI: 10.1186/1471-2431-12-112.

Murray E, McCabe P, Ballard KJ (2014). A systematic review of treatment outcomes for children with childhood apraxia of speech. Am J Speech Lang Pathol 23(3): 486-504. DOI: 10.1044/2014_ AJSLP-13-0035.

Orphanet (2009). Jacobsen syndrome. [online] [cit. 2017-12-20]. Available from: http://www.orpha.net/consor/cgi-bin/OC_Exp. php?Lng=GB\&Expert $=2308$

Preston JL, Brick N, Landi N (2013). Ultrasound biofeedback treatment for persisting childhood apraxia of speech. Am J Speech Lang Pathol 22(4): 627-643. DOI: 10.1044/1058-0360(2013/120139).

Rare Diseases Act of 2002 (2002). [online] [cit. 2017-12-20]. Available from: https://www.gpo.gov/fdsys/pkg/PLAW107publ280/html/PLAW-107publ280.htm

Sinclair DB, Snyder TJ (2005). Corticosteroids for the treatment of Landau-Kleffner syndrome and continuous spike-wave discharge during sleep. Pediatr Neurol 32(5): 300-306. DOI: 10.1016/j. pediatrneurol.2004.12.006.

Thomas DC, McCabe P, Ballard KJ (2014). Rapid Syllable Transitions (ReST) treatment for childhood apraxia of speech: the effect of lower dose-frequency. J Commun Disord 51: 29-42. DOI: 10.1016/j.jcomdis.2014.06.004.

Tisch SHD, Brake HM, Law M, Cole IE, Darveniza P (2003). Spasmodic dysphonia: clinical features and effects of botulinium toxin therapy in 169 patients - an Australian experience. J Clin Neurosci 10(4): 434-438.

Velleman SL (2003). Childhood apraxia of speech: Resource guide. Thomson, New York.

Winter J (2008). Critical review: evidence of the presence of literacy difficulties in children who have childhood apraxia of speech. [online] [cit. 2017-12-20]. Available from: https://www.uwo.ca/ fhs/lwm/ebp/reviews/2007-08/Winter,MJ.pdf 